\title{
DFT-QSAR studies on corrosion inhibition efficiency of derivatives of thiadiazole, oxadiazole and triazole
}

\author{
M.O. Abdulazeez, A.K. Oyebamiji and B. Semire* \\ Department of Pure and Applied Chemistry, Faculty of Pure and Applied Sciences, \\ Ladoke Akintola University of Technology, P.M.B 4000, Ogbomoso, \\ Oyo State, Nigeria \\ *E-mail: bsemire@lautech.edu.ng
}

\begin{abstract}
A class of organic corrosion inhibitors namely; 2,5-bis(4-dimethylaminophenyl)-1,3,4thiadiazole (DAPT), 2,5-bis(4-dimethylaminophenyl)-1,3,4-oxadiazole (DAPO), 3,5diphenyl-4H-1,2,4-triazole (DHT), 3,5-di(4-pyridyl)-4H-1,2,4-triazole (PHT), 2,5-bis(4aminophenyl)-1,3,4-oxadiazole (PAOX), 3,5-di(4-methylthiophenyl)-4H-1,2,4-triazole (4MTHT) were investigated at density functional theory (DFT) B3LYP/6-31G** (d,p) level. The calculated molecular descriptors such as the HOMO, LUMO, the dipole moment, chemical potential $(\mu)$, chemical hardness $(\eta)$, softness (s), global nucleophilicity $(N)$ and average Mulliken charges on nitrogen atoms are discussed in relation to the observed inhibitory efficiency for the compounds. The developed qualitative structural activity relationship (QSAR) models relate the calculated molecular descriptors to the corrosion efficiency; thus QSAR model predicted the experimental corrosion efficiencies. The possible sites for nucleophilic and electrophilic attacks on the compounds were analyzed through the Fukui functions.
\end{abstract}

Keywords: 1,3,4-Triazole derivatives, molecular descriptors, DFT, QSAR.

Received: May 4, 2016. Published: July 18, 2016.

doi: $\underline{10.17675 / 2305-6894-2016-5-3-5}$

\section{Introduction}

The use of organic compounds as inhibitors for aqueous corrosion of metal has been a growing interest in the industries and scientific research [1-8]. The protection of metal surfaces against corrosion is a practical means of preventing corrosion in an acidic media. The most effective inhibitors are those compounds containing heteroatoms such as nitrogen, oxygen, sulphur and phosphorus, as well as aromatic rings which block the active sites, decreasing the corrosion rate [9-13]. The compounds that contain both nitrogen and sulphur are excellent inhibition compared with compounds containing only nitrogen or sulphur $[14,15]$.

In research on organic corrosion inhibitors, attention is paid to the mechanism of adsorption as well as the relationship between inhibitor structures and their adsorption properties. It has been observed that the adsorption depends mainly on the electronic and 
structural properties of the inhibitor molecule such as functional groups, steric factors, aromaticity, electron density on donor atoms and $\mathrm{p}$ orbital character of donating electron $[16,17]$. Also, efficient inhibitors should possess plentiful p-electrons and unshared electron pairs on either nitrogen atoms or sulphur atoms of the inhibitors to the d-orbitals of iron, and by means of transference of electrons chemical adsorption may occur on the steel surface. Thus, the steel corrosion may be suppressed by the protective film on the steel surface [18]. In the selection of a suitable compound for corrosion inhibition, the geometric and the electronic properties of the compound influence the ability of the compound to cover the metal surface and the ability of the compound to react with the metal surface just therefore bind to the metal surface.

In searching for suitable organic corrosion inhibitors, several researchers have reported the role of some triazole derivatives as corrosion inhibitors on different metal surfaces and in different environments [19,20]. Thereto, Quantum chemical methods combined with experimental methods have been utilized to confirm the potential of triazole derivatives as corrosion inhibitors [21,22].

Recently, corrosion inhibitions of some triazole derivative such as 3,5-bis(n-pyridyl)4-amino-1,2,4-triazole [23], 2,5-disubstituted 1,3,4-thiadiazoles [24], 4H-1,2,4-triazole derivatives [25] and 3,5-bis (4-methoxyphenyl)-4-amino-1,2,4-triazoles [1] have been explored experimentally and theoretically. However in this work, six derivatives of triazoles: 2,5-bis(4-dimethylaminophenyl)-1,3,4-thiadiazole (DAPT), 2,5-bis(4-dimethylaminophenyl)-1,3,4-oxadiazole (DAPO), 3,5-diphenyl-4H-1,2,4-triazole (DHT), 3,5-di(4pyridyl)-4H-1,2,4-triazole (PHT), 2,5-bis(4-aminophenyl)-1,3,4-oxadiazole (PAOX), 3,5di(4-methylthiophenyl)-4H-1,2,4-triazole (4-MTHT) as shown in Figure 1 are theoretically examined. These compounds have been thoroughly investigated using various experimental methods [26] and the results revealed that these triazoles could be sued as inhibitors for iron in acidic media. However, in order to relate molecular descriptors/properties of these compounds to the experimentally observed inhibition efficiencies, quantum chemical calculations are performed on the molecules as well as development of QSAR model.

Therefore, the major aim of this paper is to use density functional theory (DFT) to calculate molecular descriptors that relate to the observed inhibition efficiencies of these triazole derivatives [26] and also to develop quantitative structural activity relationship (QSAR) model from the calculated descriptors that could predict the observed inhibition efficiencies. 
Molecule

4-MTHT<smiles>CSc1ccc(-c2nnc(-c3ccc(SC)cc3)[nH]2)cc1</smiles>

DAPO<smiles>CN(C)c1ccc(-c2nnc(-c3ccc(N(C)C)cc3)o2)cc1</smiles>

DAPT<smiles>CN(C)c1ccc(-c2nnc(-c3ccc(N(C)C)cc3)s2)cc1</smiles>

DHT<smiles>c1ccc(-c2nnc(-c3ccccc3)[nH]2)cc1</smiles>

PAOX<smiles>Nc1ccc(-c2nnc(-c3ccc(N)cc3)o2)cc1</smiles>

PHT<smiles>c1cc(-c2nnc(-c3ccncc3)[nH]2)ccn1</smiles>

\section{Optimized}
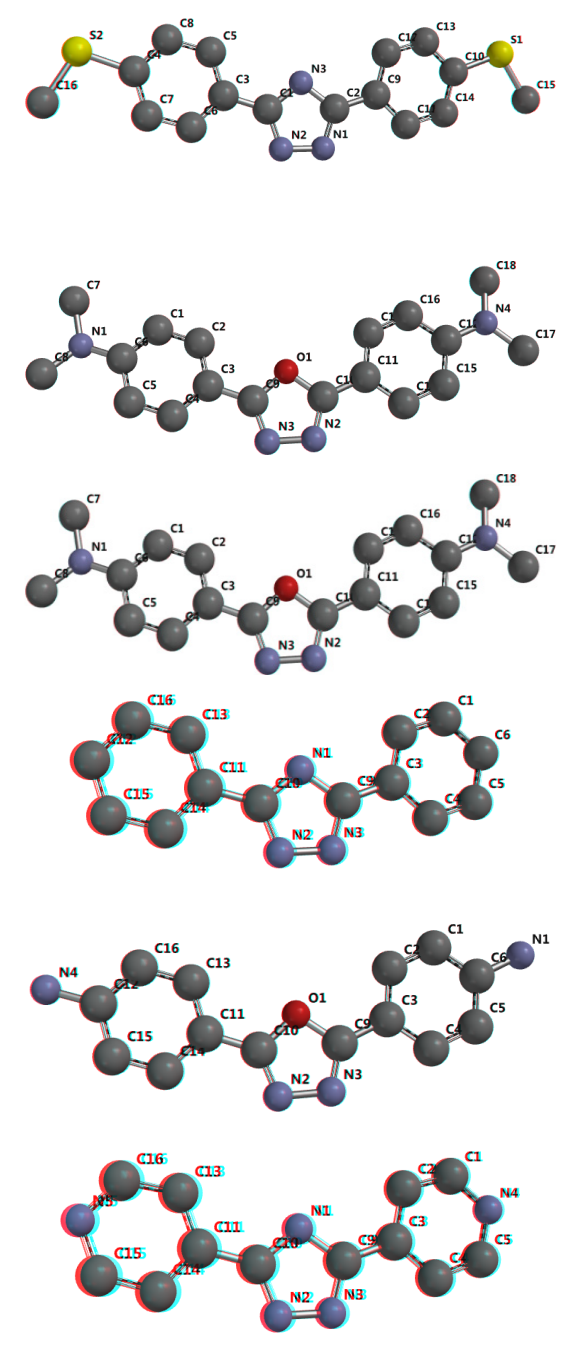

Figure 1. Schematic and optimized structures of the studied molecules.

\section{Computational details}

\subsection{Quantum chemical calculations}

Quantum chemical calculations via Density functional theory (DFT) method was used to perform geometry optimization for the molecules. Density functional theory (Beckes's three-parameter hybrid functional [27] employing the Lee, Yang and Parr correlation functional B3LYP [28] with 6-31G** basis set was used for the geometry optimization as well for energy calculation implemented in Spartan 14 software package. DFT has been a veritable method to describe the structural nature of the inhibitor in the corrosion process as well as analysing the inhibitor-surface interaction mechanism; thus DFT calculations provide theoretical information for qualitative chemical concept like electronegativity $(\chi)$, chemical hardness $(\eta)$, softness $(s)$, global electrophilicity index $(\omega)$ and local reactivities. 
The basic relationship of the conceptual DFT method to chemical reactivity is precisely the one established by Koopmans (1934), Donald, (1968), Parr et al. (1999), Domingo et al. (2002), as well as Yang and Parr, (1985) [29-33]. The chemical potential and electronegativity are related as:

$$
\mu=\frac{d E}{d n} V(r)=-\chi=-\frac{I P+E A}{2}=\frac{E_{\mathrm{HOMO}}+E_{\mathrm{LUMO}}}{2},
$$

where $E$ : is the total energy, $\mu$ : chemical potential, $N$ : number of electrons and $V(r)$ : external potential of the system.

Also chemical hardness ( $\eta$ ) was defined within the DFT as the second derivative of the energy $(E)$ with respect to $(N)$ as $V(r)$ property which measures both stability and reactivity of the molecule as:

$$
\eta=\frac{d^{2} E}{d^{2} n} V(r)=-\frac{I P+E A}{2}=\frac{E_{\mathrm{HOMO}}+E_{\mathrm{LUMO}}}{2},
$$

where $I P$ : is the amount of energy required to remove one electron from each atom in a mole of gaseous atom to produce one mole of gaseous ion with positive charge in the molecule, which is termed ionization potential. This is approximate to $-E_{\mathrm{HOMO}} ; E A$ : is the energy change that occurs/release when a gaseous atom acquires an electron to form a univalent negative ion, which is termed electron affinity, this is approximate to $-E_{\mathrm{LUMO}}$.

The global electrophilicity index and softness are calculated as $\omega=\frac{\mu^{2}}{2 \eta}$ and $s=\frac{1}{2 \eta}$ respectively.

The theoretical number of electron transfer $(\Delta \mathrm{N})$ between a molecule and iron in acidic media was calculated as: $\Delta N=\frac{\chi_{\mathrm{Fe}}-\chi_{\text {inh }}}{2\left(\eta_{\mathrm{Fe}}-\eta_{\text {inh }}\right)},[34]$.

where $\chi_{\mathrm{Fe}}$ and $\chi_{\text {inh }}$ are the absolute electronegativity of the metal (Fe) and inhibitor molecule respectively, $\eta_{\mathrm{Fe}}$ and $\eta_{\mathrm{inh}}$ are the absolute hardness of iron and the inhibitor molecule respectively. In this work, the theoretical value for $\chi_{\mathrm{Fe}}=7.0 \mathrm{eV}$ and $\eta_{\mathrm{Fe}}=0$ for the computation electron transferred.

The local electrophilicity/nucleophilicity index which is used to determine the reactivity of individual atom in the molecule as well as their effects in corrosion inhibition for a particular metal. This is determined by change in electron density for a nucleophile, $F_{(r)}^{+}$and $F_{(r)}^{-}$as the Funki functions which can be calculated by the finite differences approximation as:

$F_{(r)}^{+}=P_{N+1(r)}-P_{N(r)} \quad$ (for nucleophilic attack) [20],

$F_{(r)}^{-}=P_{N(r)}-P_{N-1(r)} \quad$ (for electrophilic attack) [28], 
where $P_{N+1(r),} P_{N(r),}$ and $P_{N-1(r)}$ are the electronic densities of anionic, neutral and cationic species respectively.

\subsection{Quantitative Structural Activity Relationship (QSAR)}

QSAR was developed to relate the structure activity relationship of molecular descriptors from quantum chemical calculations of different six pyrazole derivatives as corrosion inhibitors. In this method of analysis the model quality depends on the fitting and prediction ability. On this account, it is suitable to form several quantum chemical descriptors such as $\log P$ (substituent constant - measure of the differential solubility of a compound in two solvents and characterizes the hydrophobicity/hydrophilicity of a molecule), polarization, PSA (polar surface area), ovality, area and volume and attempt to correlate the index of these quantum chemical parameters to the experimentally determined inhibition efficiencies. In this approach, a relationship in the form of an equation is sought which correlates the molecular parameters/descriptors to the observed activity. The linear equation proposed by Lukovits (2001) is often used in the study of corrosion inhibitors to correlate the quantum molecular descriptors with the experimental inhibition efficiency of the inhibitors [35]. In order to build QSAR model and test the model workability, the data's were divided into set which was used in building the model. The linear model built using selected descriptors from the data set were used and obtained the following linear equation. The selected descriptors obtained from SPSS gives the linear equations as represented in Equation (1).

$$
\% \mathrm{IE}=\dot{\alpha}+\beta_{1} X_{1}+\beta_{2} X_{2} \ldots \ldots \ldots \beta_{n} X_{n}
$$

where $\alpha$ and $\beta$ are constants, i.e., regression coefficients determined through regression analysis, $X_{1}, X_{2} \ldots . X_{n}$ are quantum chemical index characteristics of the molecule $1,2 \ldots . n$.

\section{Result and Discussion}

\subsection{Molecular descriptors}

Molecular properties of the studied compounds provide information on the reactivity and selectivity of the compounds; such information is useful in the comparison of the trends in reactivity among different compounds and is important in the attempt to understand the interaction of the inhibitor with the metal surface. The selected molecular properties include the highest occupied molecular orbital (HOMO), the lowest unoccupied molecular orbital (LUMO), the energy of the HOMO $\left(E_{\mathrm{HOMO}}\right)$, the energy of the LUMO $\left(E_{\mathrm{LUMO}}\right)$, the energy difference between the HOMO and the LUMO $(\Delta E)$, the dipole moment, chemical potential $(\mu)$, chemical hardness $(\eta)$, softness $(s)$, global nucleophilicity $(\varpi)$ and average electron density on nitrogen atoms. The highest occupied molecular orbital (HOMO) gives information about the regions in the molecule with the most energetic electrons. These electrons are the most likely to be donated to the electron poor species. Likewise, the lowest unoccupied molecular orbital (LUMO) is the orbital that has the lowest energy and 
gives information on the regions in a molecule that have the highest tendency to accept electrons from an electron rich species. The HOMO and LUMO orbitals overlay are displayed in Figure 2.

Molecule

HOMO

LUMO

DAPO
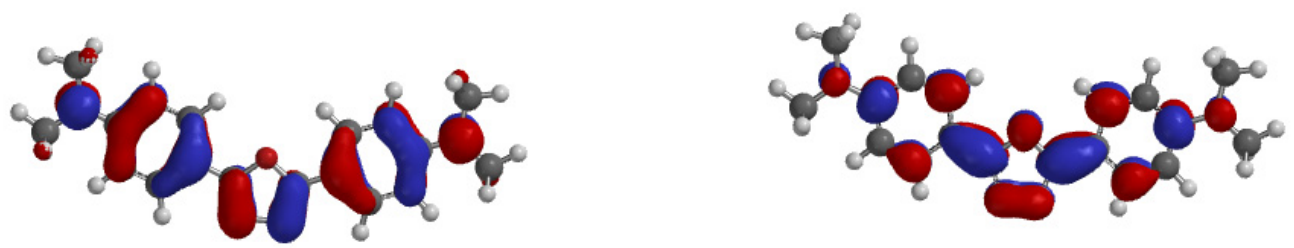

DHT
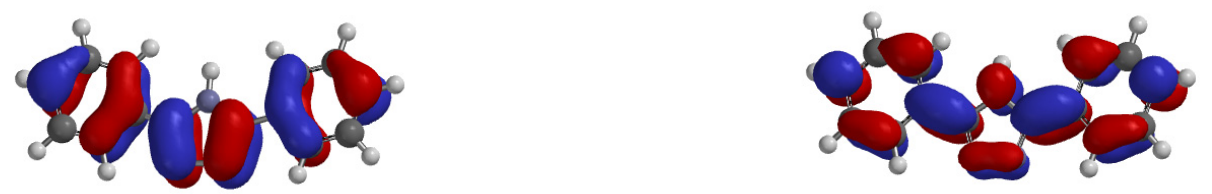

DAPT
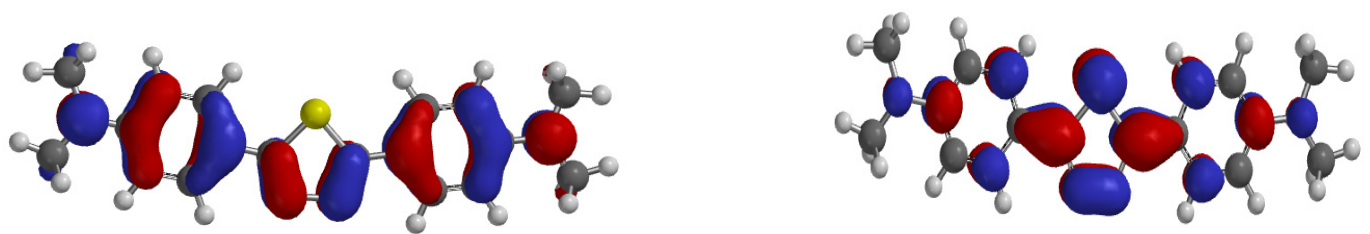

PHT
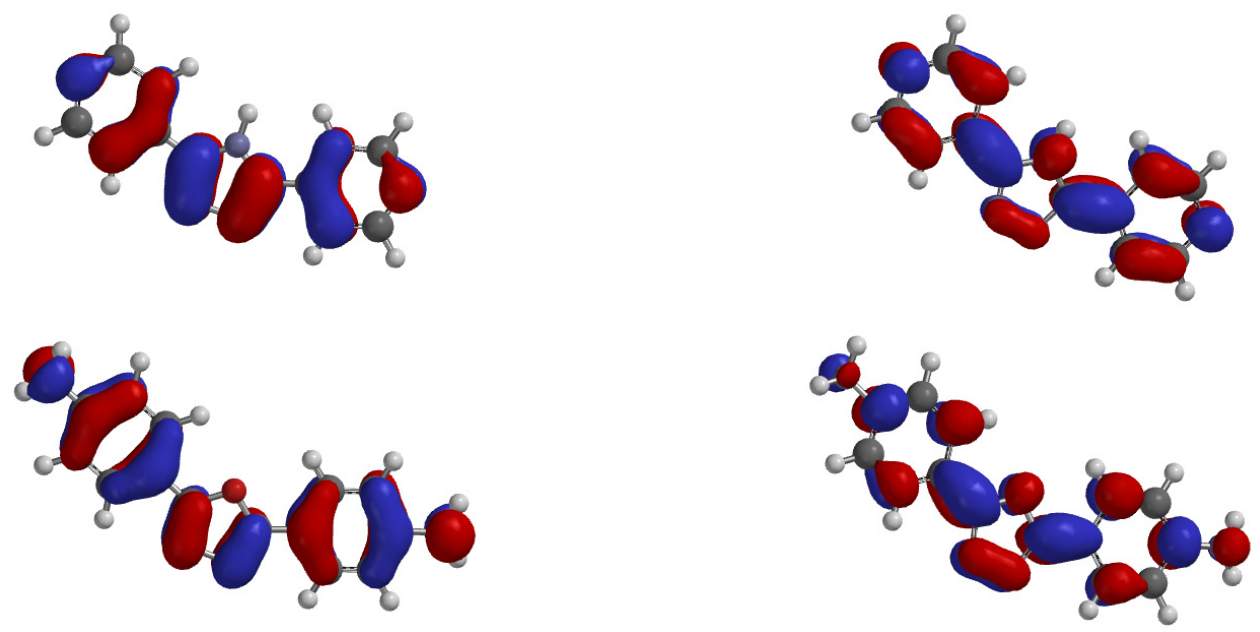

4-MTHT
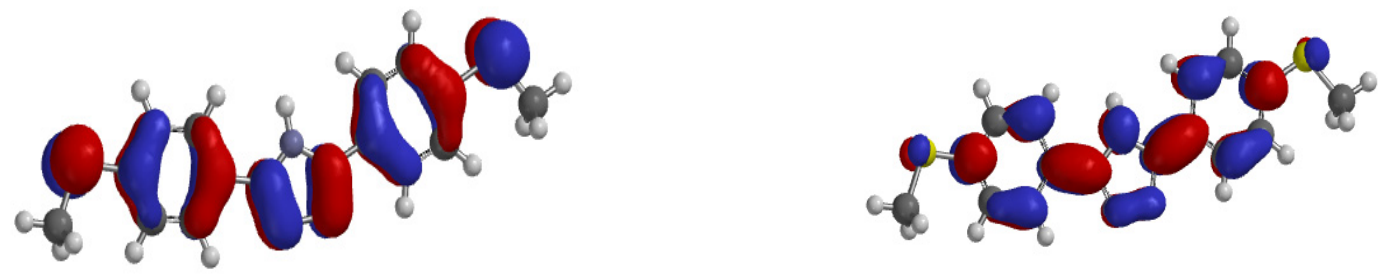

Figure 2. The highest occupied molecular orbital and the lowest unoccupied molecular orbital for the studied compounds (B3LYP/6-31G** $(\mathrm{d}, \mathrm{p})$ results). 
According to frontier molecular orbital theory (FMO) of chemical activity, transition of electron is due to interaction between highest occupied molecular orbital (HOMO) and lowest unoccupied molecular orbital (LUMO) of reacting species. Therefore the binding ability of the inhibitor to the metal surface should increase with increasing of the HOMO and decreasing of the LUMO energy values [36]. The higher the $E_{\mathrm{HOMO}}$ is, the greater is the tendency of a molecule to donate its electrons to the electron poor species.

Therefore a comparison of the $E_{\mathrm{HOMO}}$ of the studied compounds provides an indication of the molecules that would have the highest tendency to donate electrons to the metal. The calculated $E_{\mathrm{HOMO}}$ at $\mathrm{B} 3 \mathrm{LYP} / 6-3 \mathrm{G}^{* *}$ level of theory are $-5.35,-4.80,-4.83$, $-5.85,-5.12$ and $-6.69 \mathrm{eV}$ for 4-MTHT, DAPT, DAPO, DHT, PAOX and PHT respectively (Table 1).

Table 1. Quantum chemical descriptor for the studied compounds, CI is the corrosion inhibition efficiency [26].

\begin{tabular}{lcccccc}
\hline Parameters & 4-MTHT & DAPT & DAPO & DHT & PAOX & PHT \\
\hline HOMO & -5.35 & -4.80 & -4.83 & -5.85 & -5.12 & -6.69 \\
LUMO & -1.24 & -1.20 & -0.86 & -1.30 & -0.99 & -2.06 \\
Energy gap & 4.11 & 3.60 & 3.97 & 4.55 & 4.13 & 4.61 \\
Dipole moment & 2.08 & 3.34 & 5.37 & 4.77 & 4.79 & 3.44 \\
$\eta$ & 2.055 & 1.80 & 1.985 & 2.275 & 2.065 & 2.305 \\
$s$ & 0.243 & 0.277 & 0.252 & 0.219 & 0.242 & 0.217 \\
Sol. energy & -55.69 & -32.42 & -37.85 & -40.19 & -66.99 & -65.11 \\
$\mu$ & -3.295 & -3.00 & -5.69 & -3.575 & -3.055 & -4.365 \\
Ф & -2.641 & -2.5 & -8.155 & -2.81 & -2.259 & -4.133 \\
$\Delta N$ & 0.901 & 1.11 & 0.33 & 0.75 & 0.955 & 0.571 \\
$*$ Nitrogen charge & -0.376 & -0.310 & -0.369 & -0.371 & -0.366 & -0.359 \\
Area & 330.80 & 358.41 & 350.74 & 250.81 & 275.21 & 240.54 \\
Volume & 309.19 & 339.53 & 329.93 & 234.54 & 252.16 & 221.81 \\
PSA & 31.466 & 21.182 & 29.948 & 31.335 & 77.458 & 46.196 \\
Ovality & 1.50 & 1.52 & 1.52 & 1.36 & 1.43 & 1.36 \\
Log $P$ & 4.84 & 5.46 & 4.90 & 3.95 & 2.72 & 1.28 \\
Polarizability & 65.48 & 68.07 & 67.20 & 59.32 & 60.85 & 58.24 \\
Molecular Weight & 313.449 & 324.452 & 308.385 & 221.263 & 252.277 & 223.239 \\
\%CI** & 99.1 & 93.9 & 89.8 & 92.5 & 97.9 & 95.2 \\
\hline
\end{tabular}

*The electronic charge for the average nitrogen charge and **CI is the corrosion inhibition efficiency [2]. 
The experimental results showed that the percentage corrosion inhibition $(\% \mathrm{CI})$ observed for these compounds are 99.10, 93.90, 89.80, 92.50, 97.90 and 95.20 for 4MTHT, DAPT, DAPO, DHT, PAOX and PHT respectively. This implies that DAPT/PHT with highest/lowest $E_{\mathrm{HOMO}}$ value should have the highest/lowest tendency to donate its electrons to the metal surface, thereby strongly/weakly bind to the metal surface. However the trend in the $E_{\mathrm{HOMO}}$ values of these compounds does not agree completely with the trend in the inhibition efficiencies of the compounds $[37,38]$.

The energy of the LUMO $\left(E_{\mathrm{LUMO}}\right)$ provides information about the tendency of a molecule to accept electrons from an electron rich species. The lower $E_{\mathrm{LUMO}}$ is, the greater is the tendency of a molecule to accept electrons from an electron rich species. The calculated $E_{\mathrm{LUMO}}$ are $-1.24,-1.20,-0.86,-1.30,-0.99$ and $-2.06 \mathrm{eV}$ for $4-\mathrm{MTHT}$, DAPT, DAPO, DHT, PAOX and PHT respectively. In the same token, the trends in ELUMO values of these compounds are not in agreement with the observed inhibition efficiency. The energy difference between the HOMO and the LUMO $(\Delta E)$ provides information about the overall reactivity of a molecule; the smaller the $\Delta E$ value is, the greater is the reactivity of a molecule [39]. The trends in the $\Delta E$ values for the studied compounds show that PHT $(4.61 \mathrm{eV})$ should be the least reactive compound while DAPT $(3.60 \mathrm{eV})$ the most reactive compound. Therefore on interaction with the metal surface, DAPT should have the highest tendency to interact with the metal surface. The overall trend in the $E_{\mathrm{HOMO}}, E_{\mathrm{LUMO}}, \Delta E$ values of these compounds show no correlation with the trend in observed inhibition efficiencies.

The dipole moment provides information on the polarity of the molecule and it is also a good reactivity indicator, but there is no clear relationship between dipole moment and inhibition efficiency. For instance, Eddy et al. (2011) reported that dipole moment increases with the increasing in inhibition efficiency of the inhibitors [40]. Also, in another work of the same authors, it was suggested that dipole moment should decrease with the increase in the inhibition efficiency of the inhibitors [39]. To clarify this contradiction, Obi-Egbedi et al. (2011) have suggested that there is no valid correlation between dipole moment and corrosion inhibition efficiency of the inhibitors [40]. In this present study the calculated dipole moments do not show univocal trends with the inhibition efficiencies of the inhibitors (Table 1).

The number of electrons transferred $(\Delta N)$ indicates the tendency of a molecule to donate electrons. The higher the value of $\Delta N$ is, the greater the tendency of a molecule to donate electrons to the electron poor species. In the case of corrosion inhibitors, a higher $\Delta N$ implies a greater tendency to interact with the metal surface (i.e., a greater tendency to adsorb on the metal surface) indicating increase in inhibition efficiency [35]. However, in this paper, the trend in the $\Delta N$ values does not correlate well with the trend in the experimentally determined inhibition efficiency. Likewise, there is no relationship in the area, ovality, $\log P$, polar surface area (PSA), polarizability, volume, weight and observed corrosion inhibition efficiency (Table 1). 


\subsection{Fukui properties}

The use of Mullikan population analysis to estimate the adsorption centres of inhibitors has been widely reported and it is mostly used for the calculation of the charge distribution over the whole skeleton of the molecule [41]. There is a general consensus by several authors that the more negatively charged heteroatom, the more it can be adsorbed on the metal surface through the donor-acceptor type reaction [42]. It is important to consider the situation corresponding to a molecule that is going to receive a certain amount of charge at some centre and is going to back donate a certain amount of charge through the same centre or another one [43]. Parr and Yang (1989) proposed that larger value of Fukui function indicates more reactivity [44]; hence greater the value of condensed Fukui function, the more reactive is the particular atomic centre in the molecule. The local reactivity of the molecules is analyzed by means of the condensed Fukui function. The condensed Fukui function allows one to distinguish each part of the molecule on the basis of its distinct chemical behaviour [45] due to the different substituted functional group. The $f_{k}^{+}$measures the changes of density when the molecules gains electrons and it corresponds to reactivity with respect to nucleophilic attack. On the other hand, $f_{k}^{-}$ corresponds to reactivity with respect to electrophilic attack or when the molecule loss electrons.

The condensed Fukui functions of the studied molecules predicting centre for nucleophilic attack $\left(f_{k}^{+}\right)$and $f_{k}^{-}$are represented in Tables $2,3,4,5,6$ and 7. The $f_{k}^{+}$highest value is found on $\mathrm{N} 1$ and $\mathrm{N} 2$ which represent most probable nucleophilic attack center and the highest value for $f_{k}^{-}$is found at $\mathrm{O} 1$ with value of 0.009 , which represent the most probable centre for electrophilic attack for DAPO (Table 2). For 4-MTHT, most probable nucleophilic attack $\left(f_{k}^{+}\right)$and electrophilic attack $\left(f_{k}^{-}\right)$are $\mathrm{C} 8$ and $\mathrm{C} 4$ respectively (Table 3 ). Also, for PNOX the highest value for $f_{k}^{+}$is found on $\mathrm{O} 1$ with value of 0.033 (nucleophilic attack) and the highest value for $f_{k}^{-}$is found on C3 as presented in Table 4. For PHT, most probable nucleophilic attack $\left(f_{k}^{+}\right)$and electrophilic attack $\left(f_{k}^{-}\right)$are $\mathrm{C} 2$ and $\mathrm{C} 3$ respectively (Table 5) and the most probable nucleophilic attack $\left(f_{k}^{+}\right)$and electrophilic attack $\left(f_{k}^{-}\right)$are $\mathrm{C} 1$ and $\mathrm{C} 3$ respectively for DHT (Table 6). DAPT has the highest value for $f_{k}^{+}$on C3 with value of 0.009 (nucleophilic center) and $f_{k}^{-}$on $\mathrm{C} 4$ which represent the most probable electrophilic attack centre as represented in Table 8.

Table 2. Fukui indices for nucleophilic and electrophilic attacks for inhibitor DAPO.

\begin{tabular}{cccccc}
\hline АTOM & $\boldsymbol{P}_{N(r)}$ & $\boldsymbol{P}_{N+1(r)}$ & $\boldsymbol{P}_{N-\mathbf{1}(r)}$ & $\boldsymbol{f}_{\boldsymbol{k}}^{+}$ & $\boldsymbol{f}_{\boldsymbol{k}}^{-}$ \\
\hline C1 & -0.139 & -0.142 & -0.117 & -0.014 & -0.022 \\
$\mathrm{C} 2$ & -0.128 & -0.157 & -0.112 & -0.029 & -0.016 \\
C3 & 0.049 & 0.050 & 0.059 & 0.001 & -0.01 \\
C4 & -0.118 & -0.140 & -0.104 & -0.022 & -0.014 \\
C5 & -0.141 & -0.147 & -0.121 & -0.006 & -0.002 \\
\hline
\end{tabular}




\begin{tabular}{cccccc}
\hline АTOM & $\boldsymbol{P}_{N(r)}$ & $\boldsymbol{P}_{N+\mathbf{1}(r)}$ & $\boldsymbol{P}_{N-\mathbf{1}(r)}$ & $\boldsymbol{f}_{\boldsymbol{k}}^{+}$ & $\boldsymbol{f}_{\boldsymbol{k}}^{-}$ \\
\hline C6 & 0.356 & 0.313 & 0.366 & -0.043 & -0.01 \\
C9 & 0.502 & 0.442 & 0.532 & -0.06 & -0.03 \\
N1 & -0.508 & -0.508 & -0.474 & 0 & -0.034 \\
N2 & -0.508 & -0.508 & -0.474 & 0 & -0.034 \\
N3 & -0.369 & -0.414 & -0.324 & -0.228 & -0.045 \\
N4 & -0.369 & -0.414 & -0.324 & -0.228 & -0.045 \\
O1 & -0.503 & -0.534 & -0.494 & -0.031 & 0.009 \\
\hline
\end{tabular}

Table 3. Fukui indices for nucleophilic and electrophilic attacks for inhibitor 4-MTHT.

\begin{tabular}{cccccc}
\hline ATOM & $\boldsymbol{P}_{\boldsymbol{N}(\boldsymbol{r})}$ & $\boldsymbol{P}_{\boldsymbol{N}+\mathbf{1}(r)}$ & $\boldsymbol{P}_{N-\mathbf{1}(r)}$ & $\boldsymbol{f}_{\boldsymbol{k}}^{+}$ & $\boldsymbol{f}_{\boldsymbol{k}}^{-}$ \\
\hline C1 & 0.475 & 0.431 & 0.513 & -0.044 & -0.038 \\
C3 & 0.097 & 0.086 & 0.102 & -0.011 & -0.005 \\
C4 & -0.087 & -0.122 & -0.089 & -0.035 & 0.002 \\
C5 & -0.118 & -0.140 & -0.103 & -0.022 & -0.015 \\
C6 & -0.098 & -0.118 & -0.080 & -0.020 & -0.018 \\
C7 & -0.109 & -0.116 & -0.099 & -0.007 & -0.010 \\
C8 & -0.109 & -0.111 & -0.095 & -0.002 & -0.014 \\
N1 & -0.376 & -0.413 & -0.331 & -0.037 & -0.045 \\
N2 & -0.376 & -0.413 & -0.331 & -0.037 & -0.045 \\
N3 & -0.635 & -0.655 & -0.632 & -0.020 & -0.003 \\
S1 & 0.143 & 0.063 & 0.286 & -0.080 & -0.143 \\
S2 & 0.143 & 0.063 & 0.286 & -0.080 & -0.143 \\
\hline
\end{tabular}

Table 4. Fukui indices for nucleophilic and electrophilic attacks for inhibitor PNOX.

\begin{tabular}{cccccc}
\hline ATOM & $\boldsymbol{P}_{N(r)}$ & $\boldsymbol{P}_{N+\mathbf{1}(r)}$ & $\boldsymbol{P}_{N-\mathbf{1}(r)}$ & $\boldsymbol{f}_{\boldsymbol{k}}^{+}$ & $\boldsymbol{f}_{\boldsymbol{k}}^{-}$ \\
\hline C1 & -0.121 & -0.125 & 0.099 & -0.004 & -0.022 \\
C2 & -0.118 & -0.147 & -0.100 & -0.029 & -0.018 \\
C3 & 0.044 & 0.043 & 0.054 & -0.001 & -0.010 \\
C4 & -0.108 & -0.129 & -0.091 & -0.021 & -0.017 \\
C5 & -0.123 & -0.131 & -0.103 & -0.008 & -0.020 \\
C6 & 0.294 & 0.258 & 0.305 & -0.036 & -0.011 \\
C9 & 0.502 & 0.440 & 0.539 & -0.062 & -0.037 \\
\hline
\end{tabular}




\begin{tabular}{cccccc}
\hline ATOM & $\boldsymbol{P}_{N(r)}$ & $\boldsymbol{P}_{N+\mathbf{1}(r)}$ & $\boldsymbol{P}_{N-\mathbf{1}(r)}$ & $\boldsymbol{f}_{\boldsymbol{k}}^{+}$ & $\boldsymbol{f}_{\boldsymbol{k}}^{-}$ \\
\hline N1 & -0.657 & 0.680 & -0.603 & -0.023 & -0.054 \\
N2 & -0.366 & -0.414 & -0.313 & -0.048 & -0.053 \\
N3 & -0.366 & -0.414 & -0.313 & -0.048 & -0.053 \\
N4 & -0.657 & -0.680 & -0.603 & -0.023 & -0.054 \\
O1 & -0.502 & -0.535 & -0.490 & 0.033 & -0.012 \\
\hline
\end{tabular}

Table 5. Fukui indices for nucleophilic and electrophilic attacks for inhibitor PHT.

\begin{tabular}{cccccc}
\hline ATOM & $\boldsymbol{P}_{\boldsymbol{N}(\boldsymbol{r})}$ & $\boldsymbol{P}_{\boldsymbol{N}+\mathbf{1}(\boldsymbol{r})}$ & $\boldsymbol{P}_{\boldsymbol{N - 1}(\boldsymbol{r})}$ & $\boldsymbol{f}_{\boldsymbol{k}}^{+}$ & $\boldsymbol{f}_{\boldsymbol{k}}^{-}$ \\
\hline C1 & 0.096 & 0.079 & 0.115 & -0.017 & -0.019 \\
C2 & -0.141 & -0.163 & -0.118 & -0.022 & -0.023 \\
C3 & 0.128 & 0.111 & 0.123 & -0.017 & 0.003 \\
C4 & -0.115 & -0.133 & -0.086 & -0.248 & -0.029 \\
C5 & 0.089 & 0.065 & 0.105 & -0.024 & -0.016 \\
C9 & 0.483 & 0.436 & 0.557 & -0.047 & -0.074 \\
N1 & -0.628 & -0.620 & -0.620 & -0.022 & -0.008 \\
N2 & -0.359 & -0.291 & -0.291 & -0.043 & -0.068 \\
N3 & -0.359 & -0.291 & -0.291 & -0.043 & -0.068 \\
N4 & -0.426 & -0.367 & -0.367 & -0.064 & -0.059 \\
N5 & -0.426 & -0.367 & -0.367 & -0.064 & -0.059 \\
\hline
\end{tabular}

Table 6. Fukui indices for nucleophilic and electrophilic attacks for inhibitor DHT.

\begin{tabular}{cccccc}
\hline ATOM & $\boldsymbol{P}_{N(r)}$ & $\boldsymbol{P}_{N+\mathbf{1}(r)}$ & $\boldsymbol{P}_{N-\mathbf{1}(r)}$ & $\boldsymbol{f}_{\boldsymbol{k}}^{+}$ & $\boldsymbol{f}_{\boldsymbol{k}}^{-}$ \\
\hline C1 & -0.089 & -0.090 & -0.080 & -0.001 & -0.009 \\
C2 & -0.121 & -0.155 & -0.105 & -0.026 & -0.024 \\
C3 & 0.107 & 0.094 & 0.108 & -0.013 & -0.001 \\
C4 & -0.105 & -0.124 & -0.079 & -0.019 & -0.026 \\
C5 & -0.094 & -0.103 & -0.088 & -0.009 & -0.006 \\
C6 & -0.080 & -0.080 & -0.038 & -0.038 & -0.034 \\
C9 & 0.472 & 0.424 & 0.534 & -0.048 & -0.062 \\
N1 & -0.631 & -0.652 & -0.626 & -0.021 & -0.005 \\
N2 & -0.371 & -0.413 & -0.209 & -0.042 & -0.162 \\
N3 & -0.371 & -0.413 & -0.209 & -0.042 & -0.162 \\
\hline
\end{tabular}


Table 7. Fukui indices for nucleophilic and electrophilic attacks for inhibitor DAPT.

\begin{tabular}{cccccc}
\hline ATOM & $\boldsymbol{P}_{N(r)}$ & $\boldsymbol{P}_{N+1(r)}$ & $\boldsymbol{P}_{N-1(r)}$ & $\boldsymbol{f}_{\boldsymbol{k}}^{+}$ & $\boldsymbol{f}_{\boldsymbol{k}}^{-}$ \\
\hline C1 & 0.050 & 0.003 & 0.062 & -0.047 & -0.012 \\
C3 & 0.107 & 0.116 & 0.121 & 0.009 & -0.014 \\
C4 & 0.359 & 0.322 & 0.368 & -0.037 & -0.009 \\
C5 & -0.108 & -0.130 & -0.095 & -0.022 & -0.013 \\
C6 & -0.147 & -0.168 & -0.136 & -0.021 & -0.011 \\
C7 & -0.143 & -0.148 & -0.121 & -0.005 & -0.022 \\
C8 & -0.138 & -0.145 & -0.119 & -0.007 & -0.019 \\
N1 & -0.310 & -0.354 & -0.274 & -0.044 & -0.036 \\
N2 & -0.310 & -0.354 & -0.274 & -0.044 & -0.036 \\
N3 & -0.509 & -0.510 & -0.476 & -0.001 & -0.033 \\
N4 & -0.509 & -0.510 & -0.476 & -0.001 & -0.033 \\
S1 & 0.196 & 0.052 & 0.268 & -0.144 & -0.072 \\
\hline
\end{tabular}

\subsection{QSAR Modeling}

The quality of QSAR model depends on the fitting and prediction ability. Since each individual molecular descriptors calculated does not correlate with the $\% \mathrm{CI}$ of the molecule, an attempt was made to combine some of the parameters into QSAR model, this is because there might be multiple inter-related factors contributing to the effectiveness of the studied compounds as corrosion inhibitors. In this approach, a relationship in the form of an equation is sought which correlates the quantum chemical parameters to the observed activity. The linear equation proposed by Lukovits (2001) is often used in the study of corrosion inhibitors to correlate the quantum molecular descriptors with the experimental inhibition efficiency of the inhibitors [35]. The QSAR model represented in equation 4 shows that the combination of the LUMO, dipole moment, solvation energy, global nucleophilicity indices and average electronic charges on nitrogen atoms are the molecular descriptors that describe the corrosion inhibition of the compounds.

$$
\% \mathrm{CI}=99.064+3.159(\mathrm{LUMO})-1.458 \text { (D.M) }+0.155(\mathrm{~S} . \mathrm{E})+0.534(\infty)+0.618(\mathrm{~N} . \mathrm{C}) \text {, }
$$

where LUMO $(\mathrm{eV})$ is the energy of the lowest unoccupied molecular orbital, D.M is the dipole moment (Debye), S.E is the solvation energy $(\mathrm{kJ} / \mathrm{mol}), \infty(\mathrm{eV})$ is the global nucleophilicity and N.C is the average electronic charges on nitrogen atoms.

This QSAR model was used to predict percentage inhibition efficiency, the predicted $\% \mathrm{CI}$ were compared with the experimental \%CI of the compounds as shown in Table 8 and Figure 3. The QSAR model reproduced the experimental \%CI $\left(R^{2}=0.9994\right)$, the deviation is between 0.168 and 0.0034 . The test model (Equation 5) used shows that the QSAR model predicted $\% \mathrm{CI}$ is not significantly different from the experimental results. 


$$
\text { Test model }=100 \sqrt{\frac{(\text { Experimental }- \text { Predicted })^{2}}{n-1}}
$$

Table 8. Inhibition efficiency: experimental [26] and predicted values.

$\begin{array}{ccccc}\text { Compound } & \text { Experimental } & \text { Predicted } & \text { Deviation } & \text { Test model } \\ 4-\mathrm{MTHT} & 99.1 & 99.1034 & 0.0034 & 0.152 \\ \text { PAOX } & 97.9 & 98.068 & 0.168 & 7.513 \\ \text { PHT } & 95.2 & 95.204 & 0.004 & 0.178 \\ \text { DAPT } & 93.9 & 94.0415 & 0.1415 & 6.328 \\ \text { DHT } & 92.5 & 92.669 & 0.169 & 7.557 \\ \text { DAPO } & 89.8 & 89.802 & 0.002 & 0.089\end{array}$

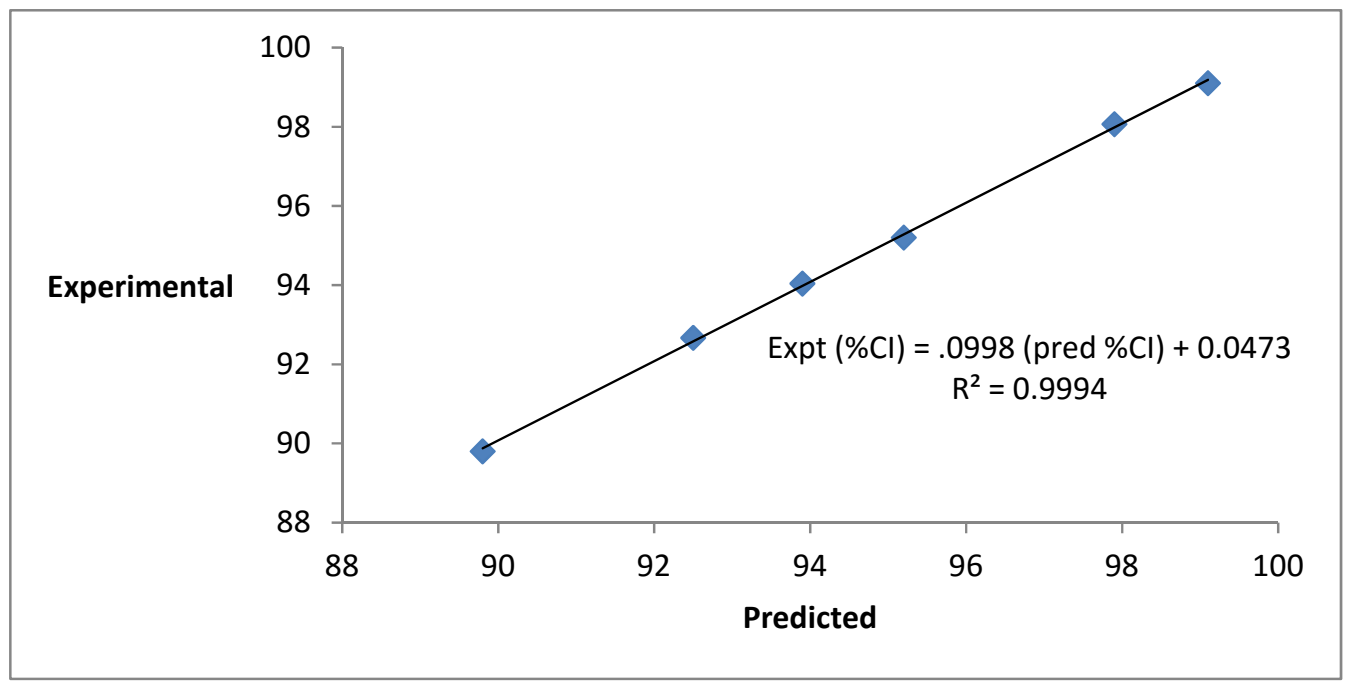

Figure 3. Correlation between experimental and predicted percentage inhibition efficiencies.

\section{Conclusion}

Quantum chemical method via B3LYP/6-31G** level of theory was used to calculate molecular descriptors/parameters such as $E_{\text {Номо }}, E_{\mathrm{LUMO}}$, energy gap $(\Delta E)$, hardness $(\eta)$, Softness $(S)$, electron affinity $(E A)$, energy gap, chemical potential, the nitrogen charge, the fraction of electron transferred $(\Delta N)$ and electrophilicity index $(\omega)$ for six triazole derivatives. The molecular descriptors calculated were used to develop QSAR model that fitted into experimentally determined corrosion efficiency. The results indicated that five to six quantum chemical parameters:the LUMO, dipole moment, solvation energy, global nucleophilicity, average electronic charges on nitrogen atoms represent molecular parameters that describe the inhibitory efficiency of the studied compounds. The QSAR model reproduced the experimental \%CI. 


\section{References}

1. F. Bentiss, C. Jama, B. Mernari, H. El Attari, L. El Kadi, M. Lebrini, M. Traisnel and M. Lagrenée, Corros. Sci., 2009, 51, 1628.

2. M. Mahdavian and S. Ashhari, Electrochim. Acta, 2010, 55, 1720.

3. A.Y. Musa, A.A.H. Kadhum, A.B. Mohamad and M.S. Takriff, Corros. Sci., 2010, 52, 3331.

4. H. Zarrok, R. Saddik, H. Oudda, B. Hammouti, A. El Midaoui, A. Zarrouk, N. Benchat and M. EbnTouhami, Pharma Chem., 2011, 3, no. 5, 272.

5. M. Benabdellah, A. Yahyi, A. Dafali, A. Aouniti, B. Hammouti and A. Ettouhami, Arab. J. Chem., 2011, 4, 343.

6. F. Zhang, Y. Tang, Z. Cao, W. Jing, Z. Wu and Y. Chen, Corros. Sci., 2012, 61, 1.

7. S.K. Shukla and M.A. Quraishi, Corros. Sci., 2009, 51, 1990.

8. L. Popova, E. Ananieva, V. Haristoval, K. Christov, K. Georgieva, E. Alexieva and Z. Stoinova, Bulg. J. Plant Physiol., Special issue, 2003, 133.

9. H. Ju, Z.P. Kai and Y. Li, Corros. Sci., 2008, 50, 865.

10. M.S. Masoud, M.K. Awad, M.A. Shaker and M.M.T. El-Tahawy, Corros. Sci., 2010, 52, 2387.

11. W. Chen, H.Q. Luo and N.B. Li, Corros. Sci., 2011, 53, 3356.

12. A. Doner, R. Solmaz, M. Özcan and G. Kardas, Corros. Sci., 2011, 53, 2902.

13. N.O. Obi-Egbedi, I.B. Obot, M.I. El-Khaiary, S.A. Umoren and E.E. Ebenso, Int. J. Electrochem. Sci., 2011, 6, 5649.

14. J. Aljourani, M.A. Golozar and K. Raeissi, Mater. Chem. Phys., 2010, 121, no. 1-2, 320.

15. Y. Abboud, A. Abourriche, T. Saffaj, M. Berrada, M. Charrouf, A. Bennamara, N. Al Himidi and H. Hannache, Mater. Chem. Phys., 2007, 105, no. 1, 1.

16. M.A. Quraishi and H.K. Sharma, 2002, Chem. Phys., 78, 18.

17. Y.I. Kuznestov, A.M. Semiletov and A.A. Chirkunov, Int. J. Corros. Scale Inhib., 2016, 5, no. 1, 31. doi: 10.17675/2305-6894-2016-5-1-3

18. S.A. Abd El-Maksoud, Int. J. Electrochem. Sci., 2008, 3, 528.

19. S.V. Lokesh, A.K. Satpati and B.S. Sherigara, The Open Electrochem. J., 2010, $2,15$.

20. R. Walker, J. Chem. Educ., 1980, 57, 789.

21. A.K. Satpati and P.V. Ravindran, Mater. Chem. Phys., 2008, 109, 352.

22. K.F Khaled, S.A Fadl-Allah and B. Hammouti, Mater. Chem. Phys., 2009, 117, no. 1, 148.

23. M. Lebrini, M. Traisnel, M. Lagrenée, B. Mernari and F. Bentiss, Corros. Sci., 2008, 50, no. 2, 473 .

24. F. Bentiss, M. Bovanis, B. Mernari, M. Traisnal, H. Vezin and M. Lagrenee, Appl. Surf. Sci., 2007, 253, 3696.

25. F. Bentiss, M. Lebrim, M. Legrame, M. Traisnel, A. Eltarota and H. Vezin, Electrochim. Acta, 2007, 52, 6865.

26. F. Bentiss and M. Lagrenée, J. Mater. Environ. Sci., 2011, 2, no. 1, 13. 
27. A.D. Becker, J. Chem. Phys., 1993, 98, no. 7, 9648.

28. C. Lee, W. Yang and R.G. Parr, J. Mol. Struct. (THEOCHEM), 1988, 163, 305.

29. T. Koopmans, Physica, 1934, 1, 104.

30. A. Yildirim and M. Cetin, Corros. Sci., 2008, 50, 865.

31. R.G. Parr, L. Szentpaly and S. Liu, J. Am. Chem. Soc., 1999, 121, 1922.

32. L.R. Domingo, M. Aurell, M. Contreras and P. Perez, J. Phys. Chem. A., 2002, 106, 6871.

33. W. Yang and R. Parr, Proc. Natl. Acad. Sci. U. S. A., 1985, 82, 6723.

34. R.G. Parr, R.A. Donnelly, M. Levy and W.E. Palk, 1978, J. Chem. Phys., 68, 3801.

35. I. Lukovits, E. Kalman and F. Zucchi, Corros. Sci., 2001, 57, 3.

36. P. Udhayakala, T.V. Rajendiran and S. Gunasekaran, J. Comput. Methods Mol. Des., 2012, 2, no. 1, 1 .

37. R.S. Oguike, A.M. Kolo, A.M. Shibdawa and H.A. Gyenna, Phys. Chem., 2013, 2013, 1.

38. B. Semire and A.O. Odunola, J. Chem. Educ., 2013, 22, no. 6, 893.

39. N.O. Eddy, Int. J. Electrochem. Sci., 2010, 39, no. 5, 288.

40. R. Hasanov, S. Bilge, S. Bilgic, G. Gece and Z. Kilic, Corros. Sci., 52, no. 3, 984.

41. M. Sahin, G. Gece, E. Karci and S. Bilgic, J. of App. Electrochem., 2008, 38, no. 6, 809.

42. G. Breket, E. Hur and C. Ogretir, J. Mol. Struct. (THEOCHEM), 2002, 578, 79.

43. B. Gomez, N.V. Likhanova, M.A. Dominguez-Aguilar, R. Martinez-Palou, A. Vela and J. Gasquez, 2006, J. Phys. Chem., 110, no. 18, 8928.

44. R.G. Parr and W. Yang, J. Chem. Phys., 1989, 530, no. 4, 88.

45. K. Fukui, T. Yonezewa and H. Shingu, J. Chem. Phys., 1952, 20, no. 4, 722. 